\title{
Association of alleles carried at TNFA -850 and BATI -22 with Alzheimer's disease
}

\author{
Anastazija Gnjec ${ }^{1,2}$, Katarzyna J D'Costa1,2, Simon M Laws ${ }^{1,2}$, Ross Hedley ${ }^{1,2}$, \\ Kelvin Balakrishnan ${ }^{1,2}$, Kevin Taddei ${ }^{1,2}$, Georgia Martins ${ }^{1,2}$, Athena Paton ${ }^{1,2}$, \\ Giuseppe Verdile ${ }^{1,2}$, Samuel E Gandy 3 , G Anthony Broe ${ }^{4}$, William S Brooks5, \\ Hayley Bennett ${ }^{4}$, Olivier Piguet ${ }^{4}$, Patricia Price ${ }^{5,6,7}$, Judith Miklossy ${ }^{8}$, \\ Joachim Hallmayer ${ }^{9}$, Patrick L McGeer ${ }^{8}$ and Ralph N Martins*1,2
}

\begin{abstract}
Address: ${ }^{1}$ Centre of Excellence for Alzheimer's Disease Research and Care, Faculty of Computing, Health and Science, School of Exercise, Biomedical and Health Sciences, Edith Cowan University, Joondalup Drive, Joondalup, 6027, WA, Australia, ${ }^{2}$ Sir James McCusker Alzheimer's Disease Research Unit, School of Psychiatry and Clinical Neurosciences, University of Western Australia, Hollywood Private Hospital, Nedlands, 6009, WA, Australia, ${ }^{3}$ Mount Sinai School of Medicine, New York, New York, 10029, USA, ${ }^{4}$ Prince of Wales Medical Research Institute, UNSW, Barker Street, Randwick, NSW 2031, Australia, ${ }^{5}$ Centre for Education and Research on Aging, University of Sydney and Concord Repatriation General Hospital, Concord, NSW, 2139, Australia, ${ }^{6}$ School of Surgery and Pathology, University of Western Australia, Nedlands, Australia, ${ }^{7}$ Department of Clinical Immunology and Biochemical Genetics, Royal Perth Hospital, Perth, WA, 6000, Australia, ${ }^{8}$ Kinsmen Laboratory of Neurological Research, Department of Psychiatry, University of British Columbia, 2255 Wesbrook Mall, Vancouver, BC, V6T 1Z3, Canada and ${ }^{9}$ Department of Genetics, and Center for Narcolepsy, Department of Psychiatry, Stanford University, Stanford, CA, 94305, USA
\end{abstract}

Email: Anastazija Gnjec - agnjec@cyllene.uwa.edu.au; Katarzyna J D'Costa - dcosta@wehi.edu.au; Simon M Laws - simon.laws@lrz.tumuenchen.de; Ross Hedley - lesley.hedley@bigpond.com; Kelvin Balakrishnan - kelvin.balakrishnan@gmail.com;

Kevin Taddei - k.taddei@ecu.edu.au; Georgia Martins - gmartins@cyllene.uwa.edu.au; Athena Paton - apaton@cyllene.uwa.edu.au; Giuseppe Verdile - g.verdile@ecu.edu.au; Samuel E Gandy - samgandy@earthlink.net; G Anthony Broe - broet@sesahs.nsw.gov.au; William S Brooks -w.brooks@unsw.edu.au; Hayley Bennett - hayley.bennett@unsw.edu.au; Olivier Piguet - o.piguet@unsw.edu; Patricia Price - patricia.price@uwa.edu.au; Judith Miklossy - miklossy@astro.tem; Joachim Hallmayer - joachimh@stanford.edu; Patrick L McGeer - mcgeerpl@interchange.ubc.ca; Ralph N Martins* - r.martins@ecu.edu.au

* Corresponding author

Published: 20 August 2008

Journal of Neuroinflammation 2008, 5:36 doi:10.1 186/1742-2094-5-36
Received: 26 June 2008

Accepted: 20 August 2008

This article is available from: http://www.jneuroinflammation.com/content/5/I/36

(C) 2008 Gnjec et al; licensee BioMed Central Ltd.

This is an Open Access article distributed under the terms of the Creative Commons Attribution License (http://creativecommons.org/licenses/by/2.0), which permits unrestricted use, distribution, and reproduction in any medium, provided the original work is properly cited.

\begin{abstract}
Background: Inflammatory changes are a prominent feature of brains affected by Alzheimer's disease (AD). Activated glial cells release inflammatory cytokines which modulate the neurodegenerative process. These cytokines are encoded by genes representing several interleukins and TNFA, which are associated with AD. The gene coding for HLA-B associated transcript I (BATI) lies adjacent to TNFA in the central major histocompatibility complex (MHC). BATI, a member of the DEAD-box family of RNA helicases, appears to regulate the production of inflammatory cytokines associated with AD pathology. In the current study TNFA and BATI promoter polymorphisms were analysed in $A D$ and control cases and BATI mRNA levels were investigated in brain tissue from $A D$ and control cases.
\end{abstract}

Methods: Genotyping was performed for polymorphisms at positions -850 and -308 in the proximal promoter of TNFA and position -22 in the promoter of BATI. These were investigated singly or in haplotypic association in a cohort of Australian $A D$ patients with $A D$ stratified on the basis of their APOE $\varepsilon 4$ genotype. Semi-quantitative RT-PCR was also performed for BATI from RNA isolated from brain tissue from $A D$ and control cases. 
Results: $A P O E \& 4$ was associated with an independent increase in risk for $A D$ in individuals with TNFA $-850 * 2$, while carriage of $B A T I-22 * 2$ reduced the risk for $A D$, independent of $A P O E \& 4$ genotype. Semi-quantitative mRNA analysis in human brain tissue showed elevated levels of BATI mRNA in frontal cortex of AD cases.

Conclusion: These findings lend support to the application of TNFA and BATI polymorphisms in early diagnosis or risk assessment strategies for $A D$ and suggest a potential role for BATI in the regulation of inflammatory reactions in AD pathology.

\section{Background}

Inflammation is a prominent pathological feature of the Alzheimer's disease (AD) brain, and might be initiated by the extracellular accumulation of amyloid $\beta(\mathrm{A} \beta)$ peptide [1]. Activated microglia and astrocytes cluster around the $\mathrm{A} \beta$ deposits and neurofibrillary tangles of $\mathrm{AD}$ brains and can release neurotoxic agents, including complement proteins and pro-inflammatory cytokines, such as interleukin (IL)-1 $\beta$, IL-6 and tumor necrosis factor-alpha (TNF $\alpha)$ [2]. Polymorphisms in genes encoding IL- $1 \alpha$, IL- $1 \beta$, IL- 6 and TNF $\alpha$ correlate with heightened risk of AD [3]. For example, IL1B -511 [4], IL6 -174 [5] and TNFA -308 [6,7] associate with increased or reduced risk of $\mathrm{AD}$. We showed that the IL1A -889 T/T and IL1B +3954 T/T genotypes mark increased risk for late-onset Alzheimer's disease (LOAD) in an Australian cohort [8].

When investigating potential genetic risk factors for $\mathrm{AD}$ pathology it is important to include established genetic risk factors. The most widely accepted genetic risk factor for late onset-forms of $\mathrm{AD}$ (LOAD) is the $\varepsilon 4$ allele of the gene encoding apolipoprotein E (APOE \&4) $[9,10]$. Two recent studies have explored a potential association between APOE $\varepsilon 4$ and the TNFA -850T ( $\left.{ }^{*} 2\right)$ promoter polymorphism in Irish [11] and Spanish [12] cohorts with conflicting outcomes. While in the Irish cohort possession of the TNFA $-850 * 2$ allele significantly increased the risk of dementia associated with APOE $\varepsilon 4$ [11], no such synergistic effect was detected in the Spanish cohort [12] suggesting that the effect could be population specific or that other genetic or environmental factors may also play a contributing role. The availability of APOE genotype data from previous studies conducted by our research group $[13,14]$ enabled us to investigate the potential link between APOE $\varepsilon 4$ and TNFA $-850 * 2$ in a well characterised Australian cohort.

TNFA $-308 * 2$ (A allele) marks susceptibility to several autoimmune and inflammatory disorders (for a review see [15]) and has higher transcriptional activity than TNFA $-308^{*} 1$ (G allele) [16,17]. However TNFA -308*2 and linked alleles may mark increased risk $[6,18]$ or protection $[7,19]$ against $A D$, so we investigated TNFA -308 alleles singly or in haplotypic combination with polymorphisms in adjacent candidate genes to elucidate associa- tions of these polymorphisms or haplotypic combinations of the respective alleles with $\mathrm{AD}$ pathology in an Australian cohort.

HLA-B associated transcript 1 (BAT1) is implicated in the regulation of several AD-associated cytokines [20,21]. BAT1 is a member of the DEAD-box family of RNA helicases, encoded in the central major histocompatibility complex (MHC) near to TNFA [22]. Members of this family are a group of highly conserved proteins involved in unwinding of RNA secondary structures [23]. DEAD-box proteins have been implicated in a number of different processes involving RNA such as mRNA stabilization [24]. Studies of anti-sense transfectants suggest BAT1 may act as a negative regulator of pro-inflammatory cytokines, namely IL-1, IL-6 and TNF $\alpha$ [20]. Furthermore, BAT1 promoter polymorphisms located at positions -22 and -348 can influence transcription through differential binding of transcription factors [21]. The $\mathrm{C}$ allele at BAT1 -22 (BAT1 $\left.-22^{*} 2\right)$ is found on a conserved ancestral haplotype associated with an increased risk of immunopathology (HLA-A1， B8，TNFA -308*2, DR3, DQ2) [21]. Neither TNFA $-308 * 2$ nor BAT1 $-22 * 2$ are unique to this haplotype, but when carried together form a haplospecific marker of a conserved block of the central MHC [25]. Here we present data from an investigation of associations between $\mathrm{AD}$, the APOE $\varepsilon 4$ genotype and carriage of TNFA $-308 * 2, T N F A-850 * 2$ and BAT1 $-22 * 2$ in a well-characterized Australian cohort. In addition, we report on BAT1 mRNA levels examined in frontal cortex (Fc) brain tissue from $\mathrm{AD}$ and control cases in order to investigate whether changes in BAT1 expression are associated with AD.

\section{Methods \\ Genotyping}

Alleles carried at BAT1 -22 (G $\rightarrow$ C) and TNFA -308 (G $\rightarrow$ A) and TNFA -850 $(\mathrm{C} \rightarrow \mathrm{T})$ promoter polymorphisms was determined in 631 individuals from a population of Northern European descent (97\% Caucasian). There were 359 control donors $(45.7 \%$ females $)$ with age at venipuncture of $76.7 \pm 13.1$ years (mean \pm SD) and $272 \mathrm{AD}$ cases $(59.2 \%$ females, age: $77.1 \pm 10.5) .391$ cases were patients recruited from a memory clinic in Perth, Western Australia (226 AD cases and 165 controls). The remainder of patients were participants in the Sydney Older Persons 
Study; a random sample of community-dwelling people aged 75 and over at recruitment. Of these, 46 were classified as having $\mathrm{AD}$ at assessment, while 194 had no cognitive impairment and were used as controls for this analysis. All studies were conducted with approval from the institutional ethics committees and with informed consent of the participants. Methods of recruitment, diagnostic criteria and $A P O E$ genotyping were as described $[13,14,26,27]$.

Genomic DNA was extracted from peripheral lymphocytes using a standard protocol [28]. BAT1 -22 alleles were determined by PCR amplification in a total volume of $20 \mu \mathrm{L}$, containing 1.0 U of Taq polymerase (Fisher Biotec, Australia), $0.2 \mathrm{mM}$ each dNTP and $3.0 \mathrm{mM} \mathrm{MgCl}_{2}$, on a Mastercycler Gradient thermal cycler (Eppendorf, Germany) as follows: 1 cycle of $95^{\circ} \mathrm{C}$ for 5 minutes, 44 cycles of $95^{\circ} \mathrm{C}$ for 30 seconds, $56^{\circ} \mathrm{C}$ for 35 seconds and $72^{\circ} \mathrm{C}$ for 40 seconds, followed by 1 cycle of $72^{\circ} \mathrm{C}$ for 10 minutes. The oligonucleotide primers, (P1) 5'-CAACCGGAAGTGAGTGCA $-3^{\prime}$ and (P2) 5'CAGACCATCGCCTGTGAA-3', were purchased from Genset Pacific Pty. Ltd (Lismore, Australia). Amplicons were digested at $37^{\circ} \mathrm{C}$ using $5 \mathrm{U}$ Alw44I (restriction sequence GTGCAC), separated on $8 \%$ non-denaturing polyacrylamide gel at $110 \mathrm{~V}$ for 1.5 hours and stained with ethidium bromide to reveal DNA fragments with migration patterns specific for each allele (Allele $1(G)=170$ base pairs (bp); Allele $2(\mathrm{C})=152 \mathrm{bp}$ and 18 bp; Figure 1 ).

TNFA -308 alleles were determined via PCR amplification in a total volume of $20 \mu \mathrm{L}$, containing $0.6 \mathrm{U}$ TAQti (Fisher Biotec, Australia), $0.2 \mathrm{mM}$ each dNTP, $1.5 \mathrm{mM} \mathrm{MgCl}_{2}$ and $0.5 \mathrm{mg} / \mathrm{ml} \mathrm{BSA}$ amplified as follows: 1 cycle of $94^{\circ} \mathrm{C}$ for 2

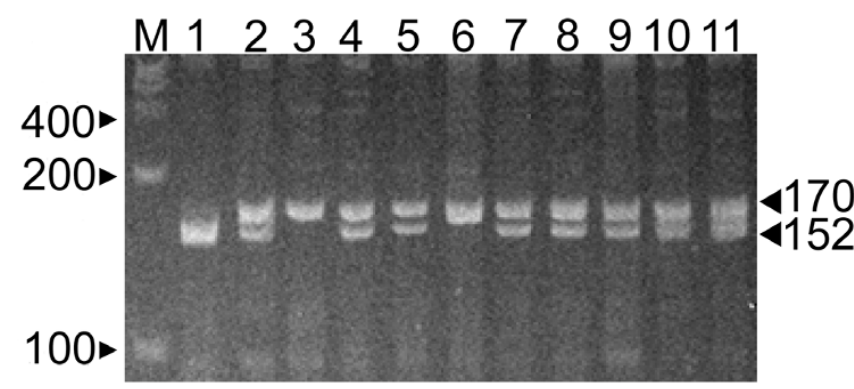

\section{Figure I}

BATI -22 G/C promoter polymorphism genotyping. A representation of a typical $-22 \mathrm{C} / \mathrm{G}$ genotyping gel produced after digested $P C R$ product was run on an $8 \%$ non-denaturing PAGE gel. $M=$ Marker ( 100 base pair marker - arrows represent 400,300 and 200 bp fragments). Black arrowheads correspond to allele fragments: $-22 \mathrm{C}=152 \mathrm{bp} \& 18 \mathrm{bp}$, and $-22 \mathrm{G}=170 \mathrm{bp}$. Lane I = -22 CC genotype. Lanes

$2,4,5,7,8,9,10$ and II $=-22$ CG genotype. Lanes 3 and $6=-22$ GG genotype. minutes, 35 cycles of $94^{\circ} \mathrm{C}$ for 30 seconds, $63^{\circ} \mathrm{C}$ for 30 seconds and $72^{\circ} \mathrm{C}$ for 30 seconds, followed by 1 cycle of $72^{\circ} \mathrm{C}$ for 5 minutes. Primers, (P1) 5'-AGGCAATAGGTTTTGAGGGCCAT-3' (underline denotes mismatch) and (P2) 5'-TCCTCCCTGCTCCGATTCCG-3', were purchased from Proligo Pty. Ltd (Lismore, Australia). Amplicons were digested at $37^{\circ} \mathrm{C}$ using $3 \mathrm{U} \mathrm{NcoI}$ (restriction sequence C $\mathbf{\Delta}$ CATGG), separated on $5 \%$ high resolution agarose gels at $280 \mathrm{~V}$ (12 minutes) and stained with ethidium bromide to reveal fragments with migration patterns specific for each allele (Allele $1(G)=88$ bp and 19 bp; Allele $2(\mathrm{~A})=107 \mathrm{bp})$.

TNFA -850 alleles were determined via PCR amplification in a total volume of $20 \mu \mathrm{L}$, containing $0.6 \mathrm{U}$ of TAQti polymerase (Fisher Biotec, Australia), $0.2 \mathrm{mM}$ each dNTP, $1.5 \mathrm{mM} \mathrm{MgCl}$ and $0.5 \mathrm{mg} / \mathrm{ml} \mathrm{BSA}$ as follows: 1 cycle of $94^{\circ} \mathrm{C}$ for 3 minutes, 35 cycles of $94^{\circ} \mathrm{C}$ for 45 seconds, $60^{\circ} \mathrm{C}$ for 30 seconds and $72^{\circ} \mathrm{C}$ for 45 seconds, followed by 1 cycle of $72^{\circ} \mathrm{C}$ for 5 minutes. Primers were modified from those initially published [27]. (P1) 5'-TCGAGTATCGGGGACCCCCCGTT-3' (underline denotes mismatch) and (P2) 5'-CCAGTGTGTGGCCATATCTTCTT-3' were purchased from Proligo Pty. Ltd (Lismore, Australia). Amplicons were digested at $37^{\circ} \mathrm{C}$ using $3 \mathrm{U}$ HincII (restriction sequence GTT $\mathbf{\Delta A C}$ ), separated on a $5 \%$ high resolution agarose gels at $280 \mathrm{~V}$ (12 minutes) and stained with ethidium bromide to reveal DNA fragments with migration patterns specific for each allele (Allele $1(\mathrm{C})=$ $105 \mathrm{bp}$ and $23 \mathrm{bp}$; Allele $2(\mathrm{~T})=128 \mathrm{bp}$ ) [29].

\section{Brain tissue samples}

Total RNA and protein was isolated from brain tissue (frontal cortex) samples from subjects with histopathologically confirmed definite $\mathrm{AD}$ and control cases without any AD pathology. Autopsy was performed within 48 hours after death. Subjects with PS1 mutations and a number of familial AD cases with APOE $\varepsilon 4$ genotypes were from local pedigrees and from the brain tissue bank of Drexel University College of Medicine (Philadelphia, PA, USA). Control brain tissue was obtained locally (Western Australia) and tissues were also received from the New South Wales (NSW) Tissue Resource Centre (Sydney, NSW, Australia), which is supported by The University of Sydney, Neuroscience Institute of Schizophrenia and Allied Disorders, National Institute of Alcohol Abuse and Alcoholism and NSW Department of Health.

\section{RNA extraction and semi-quantitative RT-PCR}

Total RNA was isolated using Trizol $^{\circledast}$ (Gibco BRL, Grand Island, New York, USA) according to manufacturer's instructions. RNA was extracted from $100 \mathrm{mg}$ of frontal cortex brain tissue from 12 cases with familial AD either with PS1 mutations or linked to inheritance of the APOE$\varepsilon 4$ allele (mean age at time of death: 63 years, range: 50 - 
77) and from 16 control cases without AD pathology (mean age at time of death: 50.25 years, range: $18-74$ years). RNA concentrations were determined spectrophotometrically and $1 \mu \mathrm{g}$ aliquots were reverse transcribed using the Omniscript ${ }^{\mathrm{TM}}$ Reverse Transcriptase Kit (QIAGEN; Victoria, Australia).

Primers required to assess the expression of BAT1 and $\beta$ ACTIN mRNA were purchased from Genset Pacific Pty. Ltd (Lismore, Australia): BAT1(F): 5'-AGAGGCTCTCTCGGTATCA-3', BAT1(R): 5'-GCTGATGTTGACCTCGAAA-3', BACTIN(F): 5'-TGGAATCCTGTGGCATCCATGAAAC-3', BACTIN(R): 5'-TAAAACGCAGCTCAGTAACAGTCCG-3'. Primers for glyceraldehyde-3-phosphate dehydrogenase $(G A P D H)$ were as previously described [30]. $5 \mu \mathrm{L}$ cDNA was amplified in a $20 \mu \mathrm{L}$ reaction on a LightCycler ${ }^{\mathrm{TM}}$ (Roche, USA). Each $20 \mu \mathrm{L}$ PCR reaction contained 1.25 mM dNTP, 20 pmol each primer, $0.25 \mathrm{mg} / \mathrm{mL}$ BSA, 1.5 units Taq Platinum polymerase and $0.5 \times$ SYBR Green (Invitrogen, USA). Amplifications of cDNA were performed as follows: Denaturation at $95^{\circ} \mathrm{C}$ for 5 minutes, followed by amplification with 44 cycles at $94^{\circ} \mathrm{C}$ for 30 seconds, annealing $\left(62^{\circ} \mathrm{C}\right.$ for BAT1, $64^{\circ} \mathrm{C}$ for $\beta$-ACTIN, and $65^{\circ} \mathrm{C}$ for $\mathrm{GAPDH}$ ) for 15 seconds and $72^{\circ} \mathrm{C}$ for 40 seconds. Amplicons were separated on 1\% TBE agarose gels and visualised by ethidium bromide staining. The quantification of cDNA was achieved with SYBR Green I dye (Sigma, USA).

Standard curves were generated using 10 -fold dilutions of a previously purified bulk cDNA PCR product (stored at a concentration of $1 \mathrm{ng} / \mu \mathrm{L}$ ) and analysed using a 'fit points' method with the LightCycler ${ }^{\mathrm{TM}}$ run software, version 4.0. Melting curve analyses were used to confirm the generation of a single product. This was further confirmed by agarose gel electrophoresis. The amplified BAT1 PCR products were sequenced using big-dye terminator chemistry on an ABI automated DNA sequencer (ABI, USA) to confirm the specific amplification of BAT1. The house keeping genes $\beta$-ACTIN and GAPDH were used for normalization of BAT1 mRNA expression. Statistical significance analysis was performed using the Mann-Whitney $U$ test.

The Statistical Package for Social Sciences (SPSS version 11.5; SPSS Inc., Chicago, Illinois, USA) was used to establish genotype and allele frequencies and to check for Hardy-Weinberg equilibrium (HWE). Initial data comparison involved Pearson's $\chi^{2}$ and odds ratio (OR) analysis of two by two contingency tables to compare the relative genotype frequencies in AD and control groups. SPSS was further employed to perform Cochran Armitage testing for trends where assumptions of HWE were not met. The same programme was also used to perform direct logistic regression analysis, where all variables were entered into the equation simultaneously to determine the overall contribution of each genotype on $\mathrm{AD}$ in this cohort, whilst controlling for established AD risk factors (age and gender). Estimation of linkage disequilibrium and analysis of haplotypes was performed using Thesias [31].

GenBank codes for genes investigated in this study include APOE (MIM: 107741, GeneID: 348), TNFA (MIM: 191160, GeneID: 7124) and BAT1 (MIM: 142560, GeneID: 7919).

\section{Results}

Pearson's chi-square $\left(\chi^{2}\right)$ and Odds ratio (OR) analysis of the BAT1 -22 $1 / 1$ and $1 / 2$ genotypes revealed a significant association between a complete absence of the BAT1 $22 * 2$ allele and $\mathrm{AD}$ (Table 1 ). However, this apparent level of protection afforded by the BAT1 $-22 * 2$ allele revealed no gene dosage effect and was limited to homozygosity of this allele (Table 1 ). Pearson's $\chi^{2}$ and OR analysis of the TNFA -308 single nucleotide polymorphism (SNP) revealed a weak yet mildly significant trend whereby possession of the $-308^{*} 2$ allele conferred protection from the development of AD. However, this was only significant when allele frequencies were analysed (Table 1 ). No significant protective effect was observed when genotype frequencies were analysed. Pearson's $\chi^{2}$ and OR analysis of genotype and allele frequencies from data generated through the genotyping of the TNFA -850 SNP revealed a strong association of the TNFA $-850 * 2 / 2$ genotype and the TNFA $-850 * 2$ allele with an increased risk for AD (Table 1).

By convention Pearson's $\chi^{2}$ and OR analysis are commonly used to evaluate data generated from large genotyping studies and explore frequency distributions. However, in order for such analysis to produce meaningful outcomes strict conditions of HWE must be met. In the current study the distributions of APOE and BAT1 -22 alleles were in $\operatorname{HWE}\left(\chi^{2}, P=.54\right.$ and $\mathrm{p}=.97$, respectively) within the control populations. However significant deviation from HWE within the control group populations was observed for TNFA -850 and TNFA -308 ( $\chi^{2}$ test, $P<$ $.005)$. Therefore, subsequent analyses employed Armitage's trend test (rather than Pearsons's $\chi^{2}$ analysis), to correct for potential type I errors associated with departure from HWE [32].

Armitage's testing for trends revealed a significant association between APOE $\varepsilon 4$ and $\mathrm{AD}\left(\chi^{2}=108.91, P<0.0001\right)$. TNFA $-850 * 2$ was also significantly associated with increased risk for $\mathrm{AD}$ while a significant protective trend was observed for BAT1 $-22 * 2$ (Table 2). The protective effect initially observed for TNFA $-308 * 2$ in the genotype and allele frequency distribution analysis (Table 1) did not reach significance using Armitage's test for trend 
Table I: Analysis of Genotype and Allele frequencies of the BATI -22, TNFA -308 and TNFA -850 polymorphisms

\begin{tabular}{|c|c|c|c|}
\hline Marker & Genotype or allele & Ctrl numbers (\%) & $A D$ numbers $(\%)$ \\
\hline \multirow[t]{5}{*}{ BATI -22} & $1 / 1$ & $144(40.1)$ & 117 (43.0) \\
\hline & $1 / 2$ & $167(46.5)$ & $138(50.7)$ \\
\hline & $2 / 2$ & $48(13.4)$ & $17(6.3)^{a}$ \\
\hline & 1 & $455(63.4)$ & $372(68.4)$ \\
\hline & 2 & $263(36.6)$ & $172(31.6)$ \\
\hline \multirow[t]{5}{*}{ TNFA -308 } & $\mathrm{I} / \mathrm{I}$ & $226(63.0)$ & $188(69.1)$ \\
\hline & $\mathrm{I} / 2$ & $104(29.0)$ & $70(25.7)$ \\
\hline & $2 / 2$ & $29(8.0)$ & $14(5.1)$ \\
\hline & 1 & $556(77.4)$ & $446(82.0)$ \\
\hline & 2 & $162(22.6)$ & $98(18.0)^{b}$ \\
\hline \multirow[t]{5}{*}{ TNFA -850} & $1 / 1$ & 287 (79.9) & $183(67.3)$ \\
\hline & $\mathrm{I} / 2$ & $61(17.0)$ & $70(25.7)$ \\
\hline & $2 / 2$ & II (3.1) & $19(7.0)^{c}$ \\
\hline & 1 & $635(88.4)$ & $436(80.1)$ \\
\hline & 2 & $83(11.6)$ & $108(19.9)^{d}$ \\
\hline
\end{tabular}

Ctrl = Control cases without $A D$ pathology

$A D=$ Alzheimer's disease cases

a BATI $-22 * 2 / 2$ versus non- $2 / 2$ in $A D, P<.005$ (Pearson $\left.\chi^{2}=8.49\right)$ OR $=0.43(95 \% \mathrm{Cl}=0.24-0.77)$

b TNFA $-308 * 2$ allele in $A D, P=.048$ (Pearson $\left.\chi^{2}=3.91\right)$ OR $=0.75(95 \% \mathrm{Cl}=0.57-1.00)$.

c TNFA -850* $(2 / 2, \mathrm{I} / 2)$ versus I/I in AD, $P<.00 \mathrm{I}$ (Pearson $\left.\chi^{2}=13.06\right) \mathrm{OR}=1.94(95 \% \mathrm{Cl}=1.35-2.78 .0)$.

d TNFA -850*2 allele in AD, $P<.001$ (Pearson $\left.\chi^{2}=16.57\right)$ OR $=1.90(95 \% \mathrm{Cl}=1.39-2.59)$.

(Table 2). This may reflect a haplotypic association with BAT1 $-22 * 2$ since the alleles are in linkage disequilibrium (LD) in the West Australian population [25].

Logistic regression analysis including age and gender associated BAT1 $-22 * 2 / 2$ with protection against AD, while TNFA $-850 * 1 / 2$ and TNFA $-850 * 2 / 2$ conferred risk (Table $3)$. These findings support Armitage's test for trend results and suggest a possible gene dosage effect for the presence of the TNFA $-850 * 2$ allele.

Additional logistic regressions analysis of interaction terms between APOE $\varepsilon 4$ and the TNFA and BAT1 SNPs showed no interactions between the effects marked by APOE \&4, and BAT1 $-22 * 2 / 2$, TNFA $-850 * 1 / 2$ or TNFA $850 * 2 / 2$. Furthermore, a stratified analysis based on $A P O E$ genotype using the Mantel-Haenszel technique showed no significant differences in Odds ratios when estimating effects on AD risk of individual SNPs versus a combination of these SNPs with APOE $\varepsilon 4$. This suggests that the observed protective effect of BAT1 $-22 * 2 / 2$ and the increased risk associated with TNFA $-850 * 2$ are independent of $A P O E \varepsilon 4$ genotype.

Table 2: Armitage test for trend for BATI and TNFA genotypes

\begin{tabular}{cccc}
\hline Marker & Genotype trend & $\chi^{2}$-value & $P$-value \\
\hline BATI -22 & $\mathrm{I} / \mathrm{I}<\mathrm{I} / 2<2 / 2$ & 7.26 & $<.05$ \\
TNFA -308 & $\mathrm{I} / \mathrm{I}<\mathrm{I} / 2<2 / 2$ & 5.28 & .07 \\
TNFA -850 & $\mathrm{I} / \mathrm{I}<\mathrm{I} / 2<2 / 2$ & 20.17 & $<.00005$ \\
\hline
\end{tabular}

BAT1 and TNFA are located in close proximity within the MHC [21,22] and their alleles are in marked LD [25]. Therefore, the computer programme Thesias [31] was used to generate LD matrices for analysis of LD and for haplotype analysis. BAT1 -22, TNFA -308 and TNFA -850 were all in LD, so haplotype frequencies were estimated under LD for all three markers and combinations of two markers. The only significant result was obtained for BAT1 $-22 * 1$ in combination with TNFA $-850 * 2(\mathrm{OR}=1.54, P<$ $0.05)$. However, the individual Odds ratios for TNFA $850 * 1 / 2$ and TNFA $-850 * 2 / 2$ were higher than for the above haplotype (i.e. individual OR for TNFA $-850 * 1 / 2=$ 1.8 and for TNFA $-850^{*} 2 / 2=2.7$ ). This indicates that the presence of BAT1 $-22 * 1$ in haplotypic association with TNFA $-850 * 2$ cannot explain the risk effects conferred by TNFA $-850 * 2$. Therefore, both the protective effect associated with BAT1 $-22 * 2$ and the increased risk associated with TNFA $-850 * 2$ are more likely due to the individual

Table 3: Direct logistic regression analysis

\begin{tabular}{cccc}
\hline Variable & Odds ratio & $P$-value & $95.0 \%$ C.I. \\
\hline BATI $-22^{*} 2 / 2^{\mathrm{a}}$ & 0.436 & $<.01$ & $0.238-0.798$ \\
$T N F A-850^{*} 1 / 2^{\mathrm{b}}$ & 1.8 & $<.005$ & $1.218-2.669$ \\
$T N F A-850^{*} 2 / 2^{\mathrm{c}}$ & 2.709 & $<.05$ & $1.260-5.824$ \\
\hline
\end{tabular}

Direct logistic regression model with Odds ratios representing risk assessment for AD.

a Homozygosity of BATI $-22 * 2$ allele (with absence of allele as reference).

b Heterozygosity of TNFA $-850 * 2$ allele (with absence of allele as reference).

c Homozygosity of TNFA $-850 * 2$ allele (with absence of allele as reference). 
SNPs themselves or a potential haplotypic association with other genes.

In order to test whether transcription of BAT1 and the homologous gene DDXL was altered in AD, mRNA levels of both BAT1 and DDXL were examined in brain frontal cortex tissue of $\mathrm{AD}$ and control cases. Analysis of BAT1 mRNA levels (Figure 2) revealed significantly elevated mRNA levels for BAT1 normalized against $\beta$-ACTIN (a) while normalization with GAPDH (b) showed marginal significance for increased BAT1 mRNA levels in the AD brains (Mann-Whitney $\mathrm{U}$ test: $P=.037$ and $P=.057$ respectively).

\section{Discussion}

$\mathrm{AD}$ is a multifactorial disorder with a number of alterations in the immune profile occurring during disease progression in both the brain [33] and the periphery [34,35]. Recently studies have reported links between risk for $\mathrm{AD}$ and polymorphisms in the promoter regions of TNFA at positions $-308[6,18]$ and $-850[11]$. The current study utilized a well characterised sample to investigate these potential associations in an Australian cohort. In addition, BAT1 has been implicated in modulation of inflammatory cytokines [20]. Therefore, the current study investigated alleles of the BAT1 -22 promoter polymorphism as a potential risk factor for $\mathrm{AD}$, singly or in haplotypic association with the TNFA promoter polymorphisms.

Analysis of individual SNPs revealed no significant association between $\mathrm{AD}$ and TNFA $-308^{*} 2$. This contrasts with reports in the literature that associate the TNFA $-308^{*} 2$ allele with either increased risk for $\mathrm{AD}[6,18]$ or protection against this disorder $[7,19]$. While data from the current study appears to be more supportive of a potential protective role for TNFA $-308 * 2$ against AD (Table 1), no conclusions can be drawn solely based on genotype and allele frequency analysis due to control group deviations from HWE that might affect the rate of type I error. However, it is possible that the inconclusive result obtained for TNFA $-308 * 2$ may be due to haplotypic associations of this polymorphism with other MHC markers such as the BAT1-22*2 allele.

In contrast to the ambiguous result obtained for TNFA $308 * 2$, analysis of individual SNPs revealed that TNFA $850 * 2$ was clearly significantly associated with increased risk for $\mathrm{AD}$. The literature shows association of the TNFA $-850 * 2$ with vascular dementia [11] and individuals at high risk for dementia, such as those with Down's Syndrome [36]. However, a clear association of TNFA -850*2 with $\mathrm{AD}$ has only previously been reported as a synergistic effect in combination with $A P O E \varepsilon 4$ in a Northern Irish population [11], while a similar study in a population
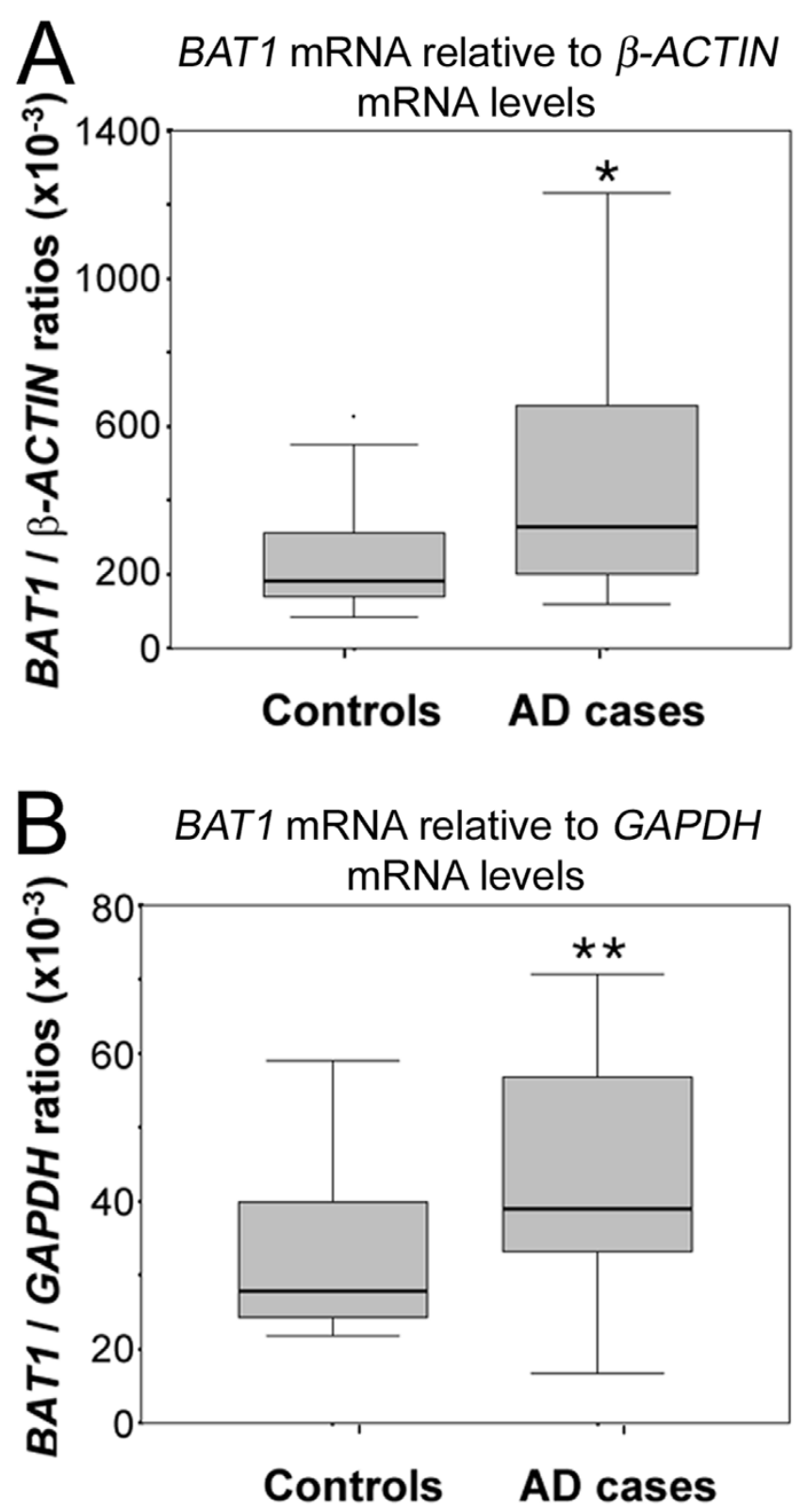

Figure 2

Semi-quantitative RT-PCR of BATI and DDXL mRNA in frontal cortex of $A D(n=12)$ and control cases $(n=$ 16). Data is represented as Box-plots showing median values and quartiles. (A) BATI mRNA levels normalized against $\beta$ ACTIN (Mann-Whitney $U$ test: $* P=.037)$, (B) BATI mRNA levels normalized against GAPDH (Mann-Whitney $U$ test: **P $=.057$ ).

from Northern Spain failed to produce evidence in support of a synergistic effect between TNFA $-850 * 2$ and APOE $\varepsilon 4$ [12]. The authors suggested that this discrepancy might reflect true genetic differences between the populations and pointed out that differences in allele frequency distributions between the two different European popula- 
tions might indicate linkage disequilibrium between the TNFA -850 and another marker that might represent the true disease causing gene [12].

The current study presents data in support of the notion that TNFA $-850 * 2$ contributes to the risk of AD independently of the APOE $\varepsilon 4$ allele. Furthermore, logistic regression analysis revealed a possible gene dosage effect with increase in copy numbers of the TNFA $-850 * 2$ allele leading to higher Odds ratios. It is, however, possible that a gene linkage with TNFA $-850 * 2$ would show a parallel OR pattern, and might account for the apparent gene dosage effect attributed to the TNFA $-850 * 2$ allele. Since all three markers investigated exerted their effects independently of APOE $\varepsilon 4$ but were found to be in LD with one another, haplotype frequencies, taking into account LD between markers, were estimated for all three MHC markers and also for combinations of two markers in order to investigate whether an $\mathrm{AD}$ risk or protection associated haplotype could be responsible for the effects observed.

Only one haplotype (BAT1 $-22 * 1$ in combination with TNFA $-850 * 2$ ) appeared to be significantly associated with risk for $\mathrm{AD}$, but the observed Odds ratio was lower for this haplotype $(\mathrm{OR}=1.54)$ than the $\mathrm{OR}$ for the single polymorphisms associated with AD risk (TNFA -850*1/2, $\mathrm{OR}=1.8$ and $T N F A-850 * 2 / 2, \mathrm{OR}=2.7)$. This indicates that, although in LD with the other two markers TNFA $850 * 2$ did not exert its risk for AD through a haplotypic association with these polymorphisms. While it cannot be entirely ruled out that linkage disequilibrium with other as yet not identified markers may be responsible for the effect observed in this investigation, the current study identifies the TNFA $-850 * 2$ allele as a candidate marker that may confer risk for AD in the Australian population. Further investigation with larger participant numbers and in other populations is clearly warranted.

While the polymorphisms in the promoter regions of TNFA are likely to directly affect transcription of the TNFA gene, ultimate levels of TNF $\alpha$ protein in tissues can also be influenced by other regulating factors such as BAT1. In the current study BAT1-22*2/2 was significantly associated with protection against the development of AD. Similar to the association between increased risk for $\mathrm{AD}$ and the presence of the TNFA $-850 * 2$ allele, the protective effect of $B A T 1-22 * 2 / 2$ was found to be independent of APOE $\varepsilon 4$ status. Furthermore, none of the estimated haplotypic associations with the two TNFA markers that are in linkage disequilibrium with $B A T 1$ have provided evidence to suggest that the effect observed for $B A T 1-22 * 2 / 2$ is due to a haplotypic association with these markers. While the possibility remains that the protective BAT1 effect might be due to LD with another gene as yet not investigated, it is also possible that BAT1 might assert an independent effect on AD risk.

A potential independent role for BAT1 in AD pathology is supported by the notion that the BAT1 -22 polymorphism may not only have the potential to affect transcription of BAT1 but, through the role BAT1 plays in mRNA stabilization, this protein may also affect translation of a number of inflammatory cytokines linked to AD pathology, including TNFA. It has previously been reported that BAT1 plays a potential role in the regulation of inflammatory cytokines, including TNFA $[20,21]$ and the BAT1 -22 allele has been associated with certain autoimmune disease susceptible ancestral haplotypes such as the 8.1 MHC AH amongst others [21]. Since BAT1 appears to regulate a number of inflammatory cytokines for which alterations are observed in AD pathology the current study is the first to provide evidence to show that a BAT1 promoter polymorphism is significantly associated with AD pathology.

It is of interest to note that for the TNFA -850 polymorphism the less frequent allele conferred risk for $\mathrm{AD}$ while the opposite was found for the less frequent allele $(\mathrm{C})$ of the BAT1 -22 polymorphism which was associated with a decreased risk for AD. This finding that the BAT1 $-22 * 2$ (C) allele is associated with protection against $\mathrm{AD}$ is in contrast to the findings for autoimmune disorders where the less common number 2 allele is implicated with ancestral haplotypes that confer increased risk [20,21]. In order to explain this phenomenon it is important to gain a better understanding of the function of BAT1. The yeast homolog of BAT1, Sub2p, has been shown to be required for mRNA export through nuclear pores $[37,38]$. Previous findings have shown that the -22 C BAT1 allele, associated with the autoimmune disease susceptible 8.1 MHC ancestral haplotype, may result in reduced BAT1 transcription [21]. However, it has also been demonstrated that both injection of excess UAP56 (BAT1) into Xenopus oocytes as well as depletion of HEL, the Drosophila homologue of UAP 56, by RNAi resulted in defects in mRNA export from the nucleus $[39,40]$. This indicates that both excess levels of BAT1 and a lack of this protein can lead to abnormalities in mRNA export and splicing. Hence, the presence of different alleles of BAT1 -22 may potentially lead to a range of different aberrations in mRNA processing resulting in a variety of different phenotypic manifestations of pathology. It is, therefore, possible that the BAT $-22 * 2$ allele per se may be protective against $\mathrm{AD}$ but still also be part of an array of SNPs that may confer risk for certain autoimmune disorders. The complexity of potential phenotypical effects as well as possible haplotypic associations of BAT1 -22 with other genes indicate that further studies are warranted to explore whether the BAT1-22*1 allele may confer an independent risk for $\mathrm{AD}$ other than 
just in haplotypic combination with TNFA $-850 * 2$ as observed in the current study.

Therefore, while the possibility of LD with other genes cannot be ruled out the current study provides evidence in support for a potential role for BAT1 in AD pathology. BAT1 -22 and TNFA -850 in combination with other biochemical and cognitive markers might serve as genetic markers for diagnostic purposes or AD risk assessment strategies. Moreover, in light of current international drug development research in the AD field, establishment of genetic profiles may help to identify individuals more likely to experience benefits from certain treatments or may prevent individuals genetically unfavourably predisposed from receiving costly, yet ineffective treatment. Since the SNPs investigated could also lead to functional differences it is of great importance to investigate phenotypical characteristics conferred by these polymorphisms.

Considering that BAT1 has a potential regulatory role for inflammatory cytokines [20,21] analysis of BAT1 mRNA and protein levels in AD brain tissue may reveal a functional role for the BAT1 protein in AD pathology. To investigate whether transcription of BAT1 was affected in $\mathrm{AD}$, levels of BAT1 mRNA were determined in brain tissue from confirmed $\mathrm{AD}$ and control cases. This revealed significantly elevated levels of BAT1 and DDXL mRNA in Fc of $\mathrm{AD}$ cases and suggests a potential functional role for BAT1 in AD pathogenesis. It is not implausible to suggest that levels of BAT1 may rise as a response mechanism to counteract the inflammatory reactions that occur in regions of $\mathrm{AD}$ pathology. However, a repetition of this study with a larger sample size to enable parametric analysis of results may help to confirm the significance of these findings.

These data are of particular interest in light of recent findings that oligonucleotides spanning the promoter polymorphism -22 to -348 region of BAT1 autoimmune disease resistant 7.1 AH bind DNA/protein complexes as shown by electrophoretic mobility shift assays [41]. At position -22 these complexes appear to include the octamer binding protein family member, transcription factor Oct1 [39]. Oct1 has been shown to bind TNFA at position $-857 \mathrm{~T}$ and can interact with the pro-inflammatory NF-אB transcription factor p65 subunit [42]. As TNFa has been implicated in inflammation observed in $A D$ brains [2] the above studies together with the current findings suggest an important association between BAT1 expression and regulation of inflammatory cytokines in the $\mathrm{AD}$ brain. The exact mechanisms of this link between BAT1 -22 promoter polymorphism and inflammatory reactions in the $\mathrm{AD}$ brain remain to be explored in future studies.
To establish the role of BAT1 in AD pathology it is imperative to examine levels of BAT1 in AD affected tissues in a larger number of cases. Apart from its presence in brain tissue, BAT1 mRNA transcripts have been detected in pancreas, kidney, skeletal muscle, liver, lung and heart [43]. The presence of BAT1 in hematopoietic cells [20] makes this protein a potential biomarker in early diagnosis or monitoring of progression of disorders with inflammatory responses, such as $\mathrm{AD}$.

\section{Conclusion}

The current study has revealed an APOE $\varepsilon 4$ independent association of TNFA $-850 * 2$ with increased risk for AD, and an APOE $\varepsilon 4$ independent association of BAT1 $-22 * 2$ / 2 with decreased risk for $\mathrm{AD}$. These findings were not enhanced by haplotype analysis of polymorphisms in linkage disequilibrium suggesting that the observed effects may have resulted from the single SNPs. Hence, these SNPs may represent valuable markers in risk assessment, prognosis and therapeutic approaches for AD. In addition, the current study has provided evidence for a novel role for BAT1 in AD pathogenesis. BAT1 may play a role in regulating the inflammatory response in $A D$ through influencing mRNA export and translation. Investigations of BAT1 promoter polymorphisms and mRNA and protein levels in other populations are clearly warranted to confirm this initial finding. Inflammatory processes form important underlying mechanisms in $\mathrm{AD}$ pathology. Elucidating the role of the currently investigated SNPs in $\mathrm{AD}$ pathology may contribute towards an understanding of the regulatory mechanisms of these events, and may provide new targets for drug development to combat AD.

\section{Competing interests}

The authors declare that they have no competing interests.

\section{Authors' contributions}

AG has isolated RNA from AD and control brain tissue and has been drafting and writing the manuscript, has performed data analysis for the mRNA work, and has been involved in interpretation of data and revising the manuscript critically for important intellectual content. KD has performed the semi-quantitative RT-PCR and data analysis and has made substantial contributions towards drafting the manuscript. SML has made substantial contributions towards genotyping, data analysis and interpretation and drafting of the manuscript. $\mathrm{RH}, \mathrm{KB}$ and KT contributed towards the genotyping process. GM and AP have been involved in the sample acquisition and/or the DNA extraction process. GV and SEG have made substantial intellectual contributions towards the manuscript. GAB, WSB, HB and OP were involved in sample acquisition and processing. PP has made substantial contributions to the concept and design of the study and the 
manuscript as expert adviser, and has contributed towards data interpretation. JM contributed towards analysing brain tissue from a substantial proportion of the cases for histopathological diagnosis. $\mathrm{JH}$ has been critically involved in statistical analyses and interpretation of data, including genotype and haplotype analyses. PM has provided substantial expert advice with regard to analysis and interpretation of data and manuscript drafting. RNM has made the most substantial contributions towards the conception and design of the study and has given final approval of the version to be published. All of the authors have read and approved the final manuscript.

\section{Acknowledgements}

This project was supported by the McCusker Foundation for Alzheimer's Disease Research, Edith Cowan University and Hollywood Private Hospital, Department of Veteran Affairs and the NHMRC. The authors would also like to acknowledge the excellent help in form of statistical analysis contributed by Dr Karen Josebury. Furthermore, the authors would like to acknowledge the Sir Zelman Cowen Universities' Fund which provided funding for collection of blood samples. We thank Dr Noel Tan for dissection and histopathological examination of brains. We also extend our thanks to Dr Clive Cooke (Queen Elizabeth Medical Centre, Perth, WA, Australia) for dissection and macroscopic examination of brains. Furthermore, we would like to thank Professor Glenda Halliday (Prince of Wales Medical Research Institute, Randwick, NSW, Australia) for valuable discussion with regard to the brain samples used.

\section{References}

I. McGeer EG, McGeer PL: The importance of inflammatory mechanisms in Alzheimer disease. Exp Gerontol 1998, 33:37I-378.

2. Gonzalez-Scarano F, Baltuch G: Microglia as mediators of inflammatory and degenerative diseases. Annu Rev Neurosci 1999, 22:219-240.

3. McGeer PL, McGeer EG: Polymorphisms in inflammatory genes and the risk of Alzheimer disease. Arch Neurol 200I, 58:1790-1792.

4. Grimaldi LM, Casadei VM, Ferri C, Veglia F, Licastro F, Annoni G, Biunno I, De Bellis G, Sorbi S, Mariani C, Canal N, Griffin WS, Franceschi M: Association of early-onset Alzheimer's disease with an interleukin-Ialpha gene polymorphism. Ann Neurol 2000, 47:36I-365.

5. Faltraco F, Burger K, Zill P, Teipel SJ, Moller HJ, Hampel H, Bondy B, Ackenheil M: Interleukin-6-174 G/C promoter gene polymorphism C allele reduces Alzheimer's disease risk. J Am Geriatr Soc 2003, 5 I:578-579.

6. Alvarez V, Mata IF, Gonzalez P, Lahoz CH, Martinez C, Pena J, Guisasola LM, Coto E: Association between the TNFalpha-308 A/G polymorphism and the onset-age of Alzheimer disease. Am J Med Genet 2002, I I 4:574-577.

7. Culpan D, MacGowan SH, Ford JM, Nicoll JA, Griffin WS, Dewar D, Cairns NJ, Hughes A, Kehoe PG, Wilcock GK: Tumour necrosis factor-alpha gene polymorphisms and Alzheimer's disease. Neurosci Lett 2003, 350:6I-65.

8. Hedley R, Hallmayer J, Groth DM, Brooks WS, Gandy SE, Martins RN: Association of interleukin-I polymorphisms with Alzheimer's disease in Australia. Ann Neurol 2002, 5 I:795-797.

9. Corder EH, Saunders AM, Strittmatter WJ, Schmechel DE, Gaskell PC, Small GW, Roses AD, Haines JL, Pericak-Vance MA: Gene dose of apolipoprotein E type 4 allele and the risk of Alzheimer's disease in late onset families. Science 1993, 26 I:921-923.

10. Craft S, Teri L, Edland SD, Kukull WA, Schellenberg G, McCormick WC, Bowen JD, Larson EB: Accelerated decline in apolipoprotein E-epsilon4 homozygotes with Alzheimer's disease. Neurology 1998, 5 I: 149-153.
11. McCusker SM, Curran MD, Dynan KB, McCullagh CD, Urquhart DD, Middleton D, Patterson CC, Mcllroy SP, Passmore AP: Association between polymorphism in regulatory region of gene encoding tumour necrosis factor alpha and risk of Alzheimer's disease and vascular dementia: a case-control study. Lancet 200I, 357:436-439.

12. Infante J, Llorca J, Berciano J, Combarros O: No synergistic effect between -850 tumor necrosis factor-alpha promoter polymorphism and apolipoprotein E epsilon 4 allele in Alzheimer's disease. Neurosci Lett 2002, 328:71-73.

13. Martins RN, Clarnette R, Fisher C, Broe GA, Brooks WS, Montgomery P, Gandy SE: ApoE genotypes in Australia: roles in early and late onset Alzheimer's disease and Down's syndrome. Neuroreport 1995, 6:1513-1516.

14. Laws SM, Taddei K, Fisher C, Small D, Clarnette R, Hallmayer J, Brooks WS, Kwok JBJ, Schofield PR, Gandy SE, Martins RN: Evidence that the butyrylcholinesterase $K$ variant can protect against late-onset Alzheimer's Disease. Alzheimer's Reports 1999, 2:219-223.

15. Wilson AG, di Giovine FS, Duff GW: Genetics of tumour necrosis factor-alpha in autoimmune, infectious, and neoplastic diseases. J Inflamm 1995, 45: I-I2.

16. Wilson AG, de Vries N, Pociot F, di Giovine FS, Putte LB van der, Duff GW: An allelic polymorphism within the human tumor necrosis factor alpha promoter region is strongly associated with HLA AI, B8, and DR3 alleles. J Exp Med 1993, 177:557-560.

17. Wilson AG, Symons JA, McDowell TL, McDevitt HO, Duff GW: Effects of a polymorphism in the human tumor necrosis factor alpha promoter on transcriptional activation. Proc Natl Acad Sci USA 1997, 94:3195-3199.

18. Collins JS, Perry RT, Watson B Jr, Harrell LE, Acton RT, Blacker D, Albert MS, Tanzi RE, Bassett SS, Mclnnis MG, Campbell RD, Go RC: Association of a haplotype for tumor necrosis factor in siblings with late-onset Alzheimer disease: the NIMH Alzheimer Disease Genetics Initiative. Am J Med Genet 2000, 96:823-830.

19. Perry RT, Collins JS, Harrell LE, Acton RT, Go RC: Investigation of association of 13 polymorphisms in eight genes in southeastern African American Alzheimer disease patients as compared to age-matched controls. Am J Med Genet 200I, 105:332-342.

20. Allcock RJ, Williams JH, Price P: The central MHC gene, BATI, may encode a protein that down-regulates cytokine production. Genes Cells 200I, 6:487-494.

21. Wong AM, Allcock RJ, Cheong KY, Christiansen FT, Price P: Alleles of the proximal promoter of BATI, a putative anti-inflammatory gene adjacent to the TNF cluster, reduce transcription on a disease-associated MHC haplotype. Genes Cells 2003, 8:403-4I2.

22. Spies T, Bresnahan M, Strominger JL: Human major histocompatibility complex contains a minimum of 19 genes between the complement cluster and HLA-B. Proc Natl Acad Sci USA 1989 , 86:8955-8958.

23. de la Cruz J, Kressler D, Linder P: Unwinding RNA in Saccharomyces cerevisiae: DEAD-box proteins and related families. Trends Biochem Sci 1999, 24:192-198.

24. Pause A, Sonenberg N: Mutational analysis of a DEAD box RNA helicase: the mammalian translation initiation factor elF-4A. Embo J 1992, I I:2643-2654.

25. Allcock RJ, Windsor L, Gut IG, Kucharzak R, Sobre L, Lechner D, Garnier JG, Baltic S, Christiansen FT, Price P: High-Density SNP genotyping defines 17 distinct haplotypes of the TNF block in the Caucasian population: implications for haplotype tagging. Hum Mutat 2004, 24:517-525.

26. Waite LM, Broe GA, Creasey H, Grayson D, Edelbrock D, O'Toole $B$ : Neurological signs, aging, and the neurodegenerative syndromes. Arch Neurol 1996, 53:498-502.

27. Waite LM, Broe GA, Creasey H, Grayson DA, Cullen JS, O'Toole B, Edelbrock D, Dobson M: Neurodegenerative and other chronic disorders among people aged 75 years and over in the community. Med J Aust 1997, 167:429-432.

28. Hixson JE, Borenstein S, Cox LA, Rainwater DL, VandeBerg JL: The baboon gene for apolipoprotein A-I: characterization of a cDNA clone and identification of DNA polymorphisms for genetic studies of cholesterol metabolism. Gene 1988, 74:483-490 
29. Kato T, Honda M, Kuwata S, Juji T, Kunugi H, Nanko S, Fukuda M, Honda $Y$ : Novel polymorphism in the promoter region of the tumor necrosis factor alpha gene: No association with narcolepsy. Am J Med Genet 1999, 88:30I-304.

30. Allcock RJ, Baluchova K, Cheong KY, Price P: Haplotypic single nucleotide polymorphisms in the central MHC gene IKBL, a potential regulator of NF-kappaB function. Immunogenetics 200I, 52(3-4):289-293.

31. Tregouet DA, Escolano S, Tiret L, Mallet A, Golmard JL: A new algorithm for haplotype-based association analysis: the Stochastic-EM algorithm. Ann Hum Genet 2004, 68:165-177.

32. Schaid DJ, Jacobsen S): Biased tests of association: comparisons of allele frequencies when departing from Hardy-Weinberg proportions. Am J Epidemiol 1999, 149:706-7।I.

33. Gupta A, Pansari K: Inflammation and Alzheimer's disease. Int J Clin Pract 2003, 57:36-39.

34. De Luigi A, Pizzimenti S, Quadri P, Lucca U, Tettamanti M, Fragiacomo C, De Simoni MG: Peripheral inflammatory response in Alzheimer's disease and multiinfarct dementia. Neurobiol Dis 2002, I I:308-3|4.

35. Sala G, Galimberti G, Canevari C, Raggi ME, Isella V, Facheris M, Appollonio I, Ferrarese C: Peripheral cytokine release in Alzheimer patients: correlation with disease severity. Neurobiol Aging 2003, 24:909-914.

36. Lucarelli P, Piciullo A, Verdecchia M, Palmarino M, Arpino C, Curatolo $P$ : The role of $\mathbf{- 8 5 0}$ tumor necrosis factor-alpha and apolipoprotein E genetic polymorphism in patients with Down's syndrome-related dementia. Neurosci Lett 2003, 352:29-32.

37. Jensen TH, Boulay J, Rosbash M, Libri D: The DECD box putative ATPase Sub2p is an early mRNA export factor. Curr Biol $200 \mathrm{I}$, II:I7II-I7I5.

38. Strasser K, Hurt E: Splicing factor Sub2p is required for nuclear mRNA export through its interaction with Yralp. Nature 200I, 4 I 3:648-652.

39. Gatfield D, Le Hir H, Schmitt C, Braun IC, Kocher T, Wilm M, Izaurralde E: The DExH/D protein HEL/UAP56 is essential for mRNA nuclear export in Drosophila. Curr Biol 200I, II:I7I6-I72I.

40. Luo ML, Zhou Z, Magni K, Christoforides C, Rappsilber J, Mann M, Reed R: Pre-mRNA splicing and mRNA export linked by direct interactions between UAP56 and Aly. Nature 200I, 413:644-647.

4I. Price $P$, Wong AM, Williamson D, Voon D, Baltic $S$, Allcock RJ, Boodhoo A, Christiansen FT: Polymorphisms at positions $\mathbf{- 2 2}$ and 348 in the promoter of the BATI gene affect transcription and the binding of nuclear factors. Hum Mol Genet 2004, 13:967-974.

42. van Heel DA, Udalova IA, De Silva AP, McGovern DP, Kinouchi $Y$, Hull J, Lench NJ, Cardon LR, Carey AH, Jewell DP, Kwiatkowski D: Inflammatory bowel disease is associated with a TNF polymorphism that affects an interaction between the OCT $\mathrm{I}$ and NF(-kappa)B transcription factors. Hum Mol Genet 2002, I I:I28I-1289.

43. Allcock RJ, Price P, Gaudieri S, Leelayuwat C, Witt CS, Dawkins RL: Characterisation of the human central MHC gene, BATI: genomic structure and expression. Exp Clin Immunogenet 1999, 16:98-106.

Publish with Bio Med Central and every scientist can read your work free of charge

"BioMed Central will be the most significant development for disseminating the results of biomedical research in our lifetime. "

Sir Paul Nurse, Cancer Research UK

Your research papers will be:

- available free of charge to the entire biomedical community

- peer reviewed and published immediately upon acceptance

- cited in PubMed and archived on PubMed Central

- yours - you keep the copyright

Submit your manuscript here:

http://www.biomedcentral.com/info/publishing_adv.asp
BiolMedcentral 